\title{
El contrapunto de la percepción: Vallejo en clave local/global
}

The counterpoint of perception: Vallejo in a local/global tone

O contraponto da percepção: Vallejo em perspectiva local/global

\section{María Helena Rueda}

SMITH COLLEGE, ESTADOS UNIDOS

Profesora del Departamento de Español y Portugués, Smith College,

Estados Unidos. PhD Hispanic Studies, Stanford University,

Estados Unidos. Ha publicado artículos en diversas revistas

especializadas y es autora de La violencia y sus huellas: una mirada

desde la narrativa colombiana (Iberoamericana Vervuert, 2011);

coeditora de Meanings of Violence in Contemporary Latin America

(Palgrave, 2011). Correo electrónico: mrueda@smith.edu

Artículo de reflexión

Documento accesible en línea desde la siguiente dirección: http://revistas.javeriana.edu.co

doi:10.11144/Javeriana.CL19-37.ecdp 


\section{Resumen}

La poca pacífica entrada al mercado global en la Colombia de los años ochenta y noventa ofrece un momento fecundo para la innovación literaria, según el estudio de María Helena Rueda "El contrapunto de la percepción: Vallejo en clave local/global". Para Rueda, el texto que lanza a Vallejo a la fama internacional, La virgen de los sicarios, constituye un holograma de un momento en el que intelectuales, artistas y líderes cívicos intentan representar realidades extremas para públicos internacionales. Nuevas subjetividades urbanas, como la del sicario, viven entre flujos mercantiles, en tanto una nueva literatura urbana colombiana se ubica en un espacio cultural que también siente el impacto de la globalización. Cuidadosamente, María Helena Rueda coloca La virgen de los sicarios en este contexto, entre el canon nacional y un público internacional que acogió con entusiasmo la "sicaresca".

Palabras clave: Fernando Vallejo; La virgen de los sicarios; globalización; sicaresca

\section{Abstract}

The restless entry into the global market in the Colombia of the 1980s and 1990s offers a fertile moment for literary innovation, pursuant to the study by María Helena Rueda "The counterpoint of perception: Vallejo in a local/ global tone". For Rueda, the text that launches Vallejo to international fame, La virgen de los sicarios, is a hologram at a time when intellectuals, artists, and civic leaders try to represent extreme realities for the international public. New urban subjectivities, as that of the hired assassin ("sicario"), live among mercantile flows, as the new Colombian urban literature places itself in a cultural space which also feels the impact of globalization. María Helena Rueda carefully places La virgen de los sicarios between the national canon and the international public that enthusiastically accepted the "hired-assassin genre" ('sicaresca').

Key words: Fernando Vallejo;

La virgen de los sicarios;

globalization; hired-assassin genre ('sicaresca')

\section{Resumo}

Segundo o estudo de María Helena Rueda "El contrapunto de la percepción: Vallejo en clave local/global", a pouco pacífica entrada do mercado global na Colômbia das décadas de 1980 e 1990 criou um contexto fecundo para a inovação literária. Para Rueda, o texto que joga Vallejo na fama internacional, La virgen de los sicarios, constitui um holograma de um momento em que intelectuais, artistas e líderes cívicos tentam representar realidades extremas para públicos internacionais. Novas subjetividades urbanas, como a do sicário, vivem entre fluxos mercantis, enquanto uma nova literatura urbana colombiana se localiza em um espaço cultural que também sente o impacto da globalização. Cuidadosamente, María Helena Rueda coloca La virgen de los sicarios neste contexto, entre o cânon nacional e um público internacional que acolheu com entusiasmo "la sicaresca".

\section{Palavras-chave: Fernando}

Vallejo; La virgen de los sicarios; globalização; sicaresca 
Vivir en Colombia a finales de la década de los ochenta y comienzos de la de los noventa implicó para muchos experimentar el terror que sembró el cartel de Pablo Escobar hasta su muerte en 1993, y para algunos - yo entre ellos - ser parte del primer grupo de lectores de La virgen de los sicarios de Fernando Vallejo, publicada en 1994. En ese momento, y en ese contexto específico, la novela entró a formar parte de una conversación más general, en la cual el fenómeno de los sicarios se veía como un síntoma del exceso que había alcanzado la violencia en Colombia. Esa mirada ubicaba la novela en el corpus de textos sobre la violencia colombiana, y la relacionaba con los (des)afectos de una sociedad que había llegado a un punto crítico de su larga guerra. Su marco de referencia era el crecimiento de la violencia asociada con el narcotráfico y su expansión decisiva hacia las áreas urbanas, principalmente Medellín y Bogotá, donde durante aquellos años rutinariamente estallaban o se desactivaban bombas en sitios públicos, y se asesinaban jueces, policías y otra serie de personajes, cuyas vidas tenían precio en el mercado de la muerte por encargo. La forma como el exaltado narrador de Vallejo conectaba esta situación con otros aspectos de la historia colombiana, entre ellos el tradicional apego de la clase dirigente por la gramática, ofrecía una perspectiva sugerente, aunque apocalíptica, sobre los desastres de la violencia en Colombia.

Era evidente, sin embargo, desde ese entonces que La virgen de los sicarios trascendía los temas y el contexto nacionales colombianos, y no solo por sus frecuentes guiños a un lector ajeno a estos. ${ }^{1}$ La novela de Vallejo representó un hito en la literatura y la cultura latinoamericanas, en una época de dramáticos cambios para la región. Fue leída como un signo de una realidad latinoamericana que se había transformado radicalmente en pocos años, marcada por las secuelas de dictaduras y guerras civiles, las crisis económicas, la oleada de reformas neoliberales, la rápida expansión del narcotráfico, la falta de opciones para los jóvenes, su conflictiva relación con las generaciones anteriores, y los cambios en los comportamientos sexuales y la visión de la sexualidad. En el contexto específico colombiano, la novela resumía ansiedades colectivas de esa época, en la cual los carteles del narcotráfico lanzaron una campaña de terror, y la vida de la

1 Desde la primera página, el narrador de Vallejo se dirige a un lector que desconoce el contexto colombiano y su lenguaje. Cuando habla de su infancia en Sabaneta, en las afueras de Medellín, se refiere a elevar un globo, y dice: “¡Pero qué saben ustedes de globos! ¿Saben qué son?” (7). Procede entonces a explicarlo, para una audiencia claramente desconocedora de los globos, que le serían familiares a cualquier lector colombiano. La novela contiene muchas referencias de este tipo. 
gente se vio marcada por la zozobra y el miedo. Las circunstancias históricas que rodearon a la novela fueron parte fundamental de su recepción y su importancia.

En 1997 salió la traducción al francés de La virgen de los sicarios, y pocos meses después se anunció que el mítico director Barbet Schroeder planeaba hacer su adaptación al cine. ${ }^{2}$ A partir de ese momento, y respaldada por la muy positiva recepción que tuvo entre el público lector colombiano, la novela de Vallejo realizó un salto decidido hacia el mercado transnacional del libro. La editorial Alfaguara, que la había publicado inicialmente solo en Colombia y México - los dos países donde Vallejo era más conocido-, expandió la edición a todo el mundo de habla hispana. Muy pronto se sucedieron las traducciones: al italiano, en 1999; al alemán, en 2000, y al inglés, en 2001. Algunas de estas versiones en otros idiomas fueron en sí mismas relativos best sellers, en especial después del estreno de la película, en 200o. La novela se convirtió en objeto de numerosos análisis académicos y entró de lleno a formar parte del canon de la literatura latinoamericana contemporánea. Los libros anteriores de Vallejo - principalmente la serie autobiográfica El río del tiempo-, fueron reeditados y crecieron en popularidad, tanto entre la crítica especializada como entre el público en general. Lo mismo se puede decir de casi todas las obras que ha publicado Vallejo desde entonces: cada una de ellas constituye un acontecimiento cultural entre los lectores de habla hispana.

Me interesa observar este salto de la novela, desde la apropiación local hasta la recepción relativamente más desapegada del circuito transnacional, por cuanto evidencia retos enfrentados por los productos culturales, particularmente aquellos que se refieren a la violencia, en tiempos de tránsito a un mercado más globalizado. Busco señalar dicho salto como algo inscrito en la novela misma, en su lenguaje, su temática y su narrador. Este último es un personaje que evoca no solo a los de otras novelas de Vallejo, sino también al personaje mediático que el autor ha creado para sí mismo, en conferencias, artículos de revista, declaraciones, cartas abiertas y entrevistas. Al igual que el narrador exaltado de sus novelas, este personaje puede ser visto como un álter ego del autor y complementa una propuesta literaria en la que se despliegan las tensiones de un difícil contrapunto entre lo local y lo global.

2 El director colombiano Luis Ospina publicó en 2008 un artículo en el que decía que Barbet Schroeder había querido desde hace años hacer una película en y sobre Colombia, incluso iniciando algunos proyectos que luego no pudieron concluirse. Dice Ospina que él le habló a Schroeder de la novela La virgen de los sicarios, el director la leyó poco después de que saliera la traducción al francés, e inmediatamente contactó a Vallejo para empezar el proyecto. La noticia se divulgó con rapidez. 
En prácticamente todos los textos de Vallejo hay una tensión entre un presente de dispersión y extrañamiento, y el apego del narrador a un espacio localizado, que se vincula con la infancia y con la noción de pertenencia asociada a ella. En La virgen de los sicarios dicha sensación de desarraigo es central a la temática: sitúa al narrador protagonista ante un contexto transformado por la injerencia de fuerzas asociadas a la globalización, entre ellas el narcotráfico. En la novela, este personaje se describe a sí mismo como un gramático que regresa a su ciudad natal después de muchos años de ausencia, para encontrarla totalmente transformada, en gran parte por el influjo de dichas fuerzas, que son disociadoras y violentas. En la película el personaje se convierte en un escritor desencantado, figura más reconocible en cualquier contexto, aunque disociada de la tradición que vincula el poder y la gramática en Colombia, lúcidamente analizada por Malcolm Deas. En ambos casos, aunque particularmente en la novela, el lenguaje del narrador está lleno de evocaciones de épocas pasadas, en las que la realidad era más contenida y localizable. Las rupturas y los cambios que encuentra a su alrededor se expresan en ese lenguaje de extremo rechazo e indignación que le son familiares a cualquier lector de Vallejo.

Vallejo usó profusamente dicho lenguaje en intervenciones públicas durante los meses que rodearon el estreno de la película de Schroeder en Colombia, en noviembre de 2000. Particularmente memorable y perturbador fue el discurso que emitió durante un Encuentro Iberoamericano de Escritores que se realizó en Bogotá en agosto de 2000, el cual fue incorporado más adelante en La desazón suprema: retrato incesante de Fernando Vallejo (2003), un documental realizado por Luis Ospina y publicado con el título "A los muchachos de Colombia", en la antología Peroratas. En ese discurso, el autor hablaba sucintamente de Colombia como un espacio de catástrofe, del que todos tendrían que irse en algún momento: "miles de secuestrados, miles y miles de asesinados, millones de desempleados, millones de exiliados, millones de desplazados, el campo en ruinas, la industria en ruinas, la justicia en ruinas, el porvenir cerrado" (18). Señalaba como culpables de la infamia, con nombre propio, a jefes del narcotráfico, guerrilleros, paramilitares y también presidentes de Colombia. Su única exhortación, en un panorama sin propuestas posibles, consistía en un llamado a no reproducirse, que Vallejo repite con frecuencia, enfrentando a la audiencia con una imposible pregunta sobre si la solución realmente reside en promover la extinción del género humano. En el caso de La virgen de los sicarios y su versión cinematográfica, la incomodidad resultante produjo efectos muy distintos entre los públicos locales y los transnacionales. Mientras que para los últimos era posible un nivel de abstracción y distanciamiento, para los primeros dicha exhortación hacia referencia directa a 
las prácticas de la violencia en la Colombia de aquellos años. El distanciamiento era virtualmente imposible.

En la época en que se estrenó la adaptación al cine de La virgen de los sicarios, estas declaraciones públicas de Vallejo produjeron un gran rechazo entre algunos sectores intelectuales colombianos. Aunque no se diferenciaban demasiado de las afirmaciones del narrador de la novela, se las veía como riesgosas al ser emitidas en la voz del propio autor, en lugar de bajo el velo de la ficción. ${ }^{3}$ Eran tiempos difíciles en Colombia. Las ciudades aún vivían las secuelas de la campaña terrorista de Pablo Escobar y en el campo la guerra se recrudecía. La guerrilla había aumentado su poder tras el despeje de la zona de El Caguán por parte del entonces presidente Andrés Pastrana, en sus intentos de establecer diálogos de paz. Aumentaron los secuestros y varias carreteras del país se volvieron intransitables por la presencia constante de retenes guerrilleros y paramilitares. Se trataba de una época en la que prevalecía una sensación de vulnerabilidad, ante la cual el tono apocalíptico de los planteamientos de Vallejo parecía ir en contra de cualquier propuesta constructiva para reparar la sensación de catástrofe que predominaba en la sociedad. Fue un argumento de ese tipo, que respondía principalmente a las declaraciones del escritor, lo que llevó a que el periodista Germán Santamaría publicara en la Revista Diners su hoy bien conocida columna "Prohibir el sicario", en la que llamaba a boicotear y ojala prohibir la película de Schroeder en Colombia, lo cual generó una inmediata respuesta en otras columnas de opinión, que en su gran mayoría condenaban a Santamaría y defendían la película, con diversos argumentos relativos a un cierto moralismo que se percibía en la columna. ${ }^{4}$ Pero más que problemas morales, a Santamaría le preocupaba la representación negativa de Colombia en un producto cultural destinado a públicos extranjeros. Su columna basa algunas de sus advertencias

3 En referencia a la desazón que causaron las palabras de Vallejo en el contexto de la guerra colombiana, Erna Von der Walde dice: "Convertido en figura pública, Vallejo ha asumido este tono de odio permanente, de misoginia rampante, de exaltación violenta en un ambiente atravesado en todas sus instancias por la violencia" (38). Aclarando que se trata de un muy legítimo juego literario posmoderno en el que se mezclan "autor" y "escritor", Von der Walde agrega: "No deja de plantear cuán problemático es esto en una situación de guerra como la que se enfrenta hoy en Colombia" (38).

4 Algunos de los intelectuales, escritores y periodistas colombianos que respondieron a la columna de Germán Santamaría fueron María Isabel Rueda, Antonio Caballero, Óscar Collazos, Jorge Franco, Daniel Samper Pizano, Reinaldo Spitaletta y Luis Ospina (cineasta). Un artículo de Semana resumía la polémica, bajo el título "Fuera de foco". También en Semana se publicó un debate entre tres intelectuales al respecto, con el título "La Virgen desde dentro", dos de ellos defendían la película y otro la condenaba. 
en el hecho de que la película ha recorrido escenarios como Venecia y París. En ese sentido, vale la pena dar una nueva mirada a esa controversia.

En los primeros años del siglo XXI, la producción cinematográfica de América Latina vivió una internacionalización sin precedentes, en gran parte como resultado de aquella serie de fenómenos que, en conjunto, reciben el vago apelativo de globalización. No voy a detenerme aquí en el análisis de este proceso, que ha sido ya ampliamente estudiado en muchos lugares. ${ }^{5}$ Baste con decir que en dicho escenario el cine aparece como uno de los productos culturales más asociados con un cierto posicionamiento de las industrias nacionales en los escenarios del intercambio económico globalizado. Pocos años después de que se exhibiera por primera vez La virgen de los sicarios, Colombia promulga su Ley de Cine de 2003, que contribuye a un fomento sin precedentes de la producción de películas en el país. Dicha ley se basa en gran parte en un esquema de coproducciones con otros países, y tiene un paralelo con leyes similares emitidas en otros países de América Latina. Se creó a raíz de ella el Fondo de Fomento Cinematográfico, cuya administración fue asumida por una entidad gubernamental llamada Proimágenes, creada en 1997 con la intención de promover la "internacionalización del cine colombiano". 6

Todo este proceso ocurre en un momento en el cual las imágenes de Colombia que circulan por el mundo tienen que ver principalmente con el narcotráfico y la violencia asociada a él. En un contexto neoliberal y globalizado, donde se impulsan la transnacionalización de la economía y la cultura, esa circulación tiene efectos directos sobre en el posicionamiento de la realidad colombiana en el imaginario global. Influye también de manera significativa en la configuración de las subjetividades de quienes aparecen representados en esas imágenes. Esto resulta particularmente relevante en referencia a quienes vivirán el futuro ideado por ese escenario visual, es decir, la población más joven, cuya subjetividad se encontraría en formación y cuya vida adulta estaría marcada por el proceso. La indagación sobre la subjetividad de los jóvenes, en un contexto donde la tensión entre lo local y lo global se resuelve en violencia, resulta central a la temática de La virgen de los sicarios. De muy diferentes maneras los jóvenes aparecen de hecho referidos tanto en el discurso de Vallejo que se dirige a "los muchachos de Colombia" como

5 Sobre el tema de la globalización en el cine latinoamericano véanse, por ejemplo, los textos de Néstor García Canclini y Ana Rosas Mantecón, Gonzalo Aguilar, Deborah Shaw, Kathleen Newman y Natasa Durovicova, Andréa Franca y Denilson Lopes, Laura Podalski y Nayibe Bermúdez Barrios.

6 La cita es tomada de la descripción proporcionada por Proimágenes, bajo el título "Qué es Proimágenes", en la página web de la entidad: http://proimagenescolombia.com. 
en la columna de Santamaría, quien dice que se deberían prohibir la novela de Vallejo y su versión cinematográfica "por el daño y la desorientación que puede sembrar en cierta juventud colombiana" (5). Dicha alusión a los jóvenes resulta significativa en el contexto de la inquietud por el futuro que producen las épocas de crisis. Los jóvenes son no solo quienes vivirán las consecuencias de esa crisis, sino también los que en algún momento podrían dar testimonio de ella.

En los años que han transcurrido desde entonces, la mayor parte de la crítica especializada y el periodismo de opinión siguen clasificando la columna de Santamaría como reaccionaria y moralista, o simplemente ingenua, en cuanto cumplió precisamente el objetivo contrario al buscado, pues en últimas ayudó a aumentar la popularidad de la película - como lo admitió el propio Barbet Schroeder- ${ }^{7} \mathrm{Si}$ tenemos en cuenta las tensiones entre la significación local y transnacional de los productos culturales que circulan en el mercado global, especialmente aquellos que tienen que ver con la violencia, podemos hoy pensar que el llamado de Santamaría tenía que ver con algo más que una simple censura moral a la película. La condena con la que iniciaba la columna no se refería tanto a las transgresiones que se presentaban en la película - y que repetían, en una versión incluso moderada, las de la novela-, sino al dinero que Fernando Vallejo estaba recibiendo a cambio de sus asaltos lingüísticos a la violencia colombiana. Tras un llamado directo a "sabotear, ojala prohibir, la exhibición pública en Colombia de la película La virgen de los sicarios", Santamaría comenzaba su columna con un reclamo referente al aspecto financiero: "Vallejo vino al encuentro de escritores de Bogotá por un salario de cinco mil dólares, recibió atenciones de cinco estrellas, solo para lanzar una de las diatribas más siniestras contra Colombia" (5). Pasaba más adelante a decir, quizás penosamente consciente del efecto publicitario que tendría su columna: "No vamos con ingenua morbosidad a resumir más la película para estimular las entradas. Porque de esto se trata"(5). Y sobre Vallejo: "Odiando a este país a morir, de la misma manera que vino por los dólares oficiales para lanzar bazofia contra Colombia, ahora quiere regresar por la gran taquilla" (5). Sus repetidas referencias al dinero que Vallejo recibe por su obra revelan que su crítica viene no tanto de una condena al uso de una temática de violencia porque lo considera inmoral, sino porque desaprueba su mercantilización.

7 Sobre el efecto que tuvo la columna de Santamaría en la recepción de la película, véase el texto de Gastón Alzate. También la entrevista que le hizo Ken Foster a Barbet Schroeder, en la que el director afirma que Germán Santamaría les hizo un favor con su columna, pues a raíz de ella aumentó inmensamente la popularidad de la película en Colombia. 
No es un secreto que la obra de Vallejo provoca, a la vez, sentimientos de desagrado y admiración. Dejarse llevar por los primeros y hacer un llamado a prohibirla o boicotearla equivale a establecer una posición defensiva ante la incomodidad que produce su propuesta literaria, la cual puede ser en cambio elogiada por esta capacidad de involucrar activamente al lector. Por esta razón, entre otras muchas, es imposible defender la columna de Santamaría. Es cierto, además, que Vallejo basa gran parte de su propuesta en el escándalo que despiertan sus declaraciones, no solo contra el país en que nació, sino también contra la religión, las mujeres, la reproducción de la especie humana, la ciencia, etc. Santamaría solo se ocupa, como lo hago yo en este artículo, de las referencias a Colombia y sus violencias; pero es importante tener en cuenta que este estilo de Vallejo no se limita a este tema. Aun así, y como he señalado antes, fue realmente con La virgen de los sicarios y su violencia como se abrieron para Fernando Vallejo de forma contundente las puertas de la popularidad en el mercado del libro, tanto local como internacionalmente. Con esto en mente, vale la pena revisitar la indignación de Santamaría ante aquello que él percibe como la mercantilización de las temáticas de violencia por parte de Vallejo, y sobre todo como la vincula con sus efectos en la juventud colombiana.

Esta referencia resulta significativa si consideramos a los sicarios como parte de esa juventud que preocupa a Santamaría. Los sicarios colombianos de finales de la década de los ochenta y principios de la de los noventa eran jóvenes plenamente insertos en las fuerzas de la economía globalizada. Por una parte, el dinero que recibían por el oficio de matar provenía del tráfico internacional de drogas. Por otra, formaban parte de una generación que comenzaba a definir sus identidades en torno al consumo, particularmente el de objetos asociados a marcas transnacionales. Es este un aspecto central a la forma como son caracterizados por el narrador los muchachos de La virgen de los sicarios. Cuando este conoce al segundo sicario con el que se vincula sexualmente, tras la muerte del primero, le pide que escriba qué espera de la vida y su respuesta es: "Unos tenis marca Reebok y unos jeans Paco Ravanne. Camisas Ocean Pacific y ropa interior Kelvin Klein. Una moto Honda, un jeep Mazda..." (107). Esa globalización precaria, definida por el tráfico y el consumo, los situaba en el centro de una dinámica que los llevaría a una vida violenta, pero no solo como resultado del reconfigurado escenario económico de la globalización, sino también por las circunstancias locales que les situaban en una posición vulnerable. En el entrecruzamiento de las fuerzas globalizadas y las violencias locales se entiende su situación simultánea de agresión y vulnerabilidad extremas, tal como es recreada en La virgen de los sicarios. 
Aunque se ha acusado a la novela de Vallejo de exagerar la criminalidad de estos jóvenes, lo cierto es que su versión no estaba demasiado lejos de la realidad. Es además diciente que la actitud de su narrador ante los sicarios, mezcla de rechazo y fascinación, tuvo un paralelo real entre la población que conoció las historias de estos jóvenes a través los medios de comunicación, primero a nivel local y luego en varias instancias transnacionales. A comienzos de la década de los noventa la figura del sicario se hizo emblemática en Colombia, porque parecía resumir las ansiedades de una sociedad que a causa de la violencia perdía la fe en el futuro. Empleados por un tiempo como asesinos a sueldo por los carteles de la droga, los sicarios eran adolescentes provenientes de las llamadas comunas, barrios marginales de Medellín marcados por el desempleo y la vulnerabilidad. Inmersos en un mundo en el que la mayoría se asesinarían unos a otros antes de cumplir veinte años, esos jóvenes adolescentes tenían pocas razones para hacer planes más allá del presente. En la Colombia de esos tiempos, su situación fue inicialmente documentada en varias crónicas periodísticas y en dos obras que tuvieron mucha difusión e impacto: el libro No nacimos pa' semilla (1990), de Alonso Salazar, y la película Rodrigo D: no futuro (1990), de Víctor Gaviria. En ellos, los sicarios aparecían como símbolo de la extrema desolación a la que se había llegado por ese entonces, en una guerra donde se entrecruzaban el narcotráfico, las guerrillas, los paramilitares y el Estado. Parecían representar también el malestar creado por la ola de reformas neoliberales que se extendía por todo el continente en esos tiempos, que pauperizaba a la población marginada, redefinía las prácticas de la violencia y rearticulaba los comportamientos en torno al consumo.

Aunque fenómenos transnacionales como el narcotráfico y la neoliberalización de la economía estaban en el transfondo de estas referencias iniciales a los sicarios, en ellas se resaltaban principalmente los aspectos locales de la situación. Se la veía como algo derivado de la trayectoria histórica de la nación colombiana y vinculado con una cultura localizada en Medellín, como marco de referencia inmediato. Tanto el libro de Salazar como la película de Gaviria tuvieron, sin embargo, mucha difusión más allá de las fronteras colombianas. El primero fue rápidamente traducido, primero al alemán, en 1991, luego al inglés y al francés, en 1992, y más tarde al italiano, en 1993. La película de Gaviria, por su parte, circuló con relativo éxito en varios festivales internacionales y obtuvo la primera nominación de una película colombiana a la codiciada Palma de Oro del Festival de Cannes, en 1990. En el contexto local, por otra parte, estas dos obras circularon profusamente. No nacimos pa' semilla fue un verdadero best seller local, con tres ediciones agotadas en los primeros cuatro meses tras su lanzamiento. 
Rodrigo D no futuro, por su parte, tuvo más de 160000 espectadores en Colombia, cifra nada deleznable para una cinta dura y difícil de entender. ${ }^{8}$ El gran interés despertado por estas obras revela una audiencia a la cual la situación de los sicarios le hablaba de ansiedades relacionadas con la violencia que se vivía en la sociedad colombiana.

En este contexto, en una nota periodística que reseñaba la publicación de La virgen de los sicarios, Héctor Abad Faciolince acuñó el término sicaresca, para referirse a todos los materiales que estaban apareciendo en la Colombia de ese entonces sobre el tema de los sicarios de Medellín. Faciolince decía al respecto: "La sicaresca es una tremenda moda literaria paisa que revela no la pobreza de nuestra narrativa sino la de nuestra realidad: pelaítos sin semilla que duran poco en sus historias callejeras". El énfasis estaba aquí en la forma como los sicarios reflejaban la situación extrema de violencia que se vivía en Colombia. El interés de sociólogos, escritores, cineastas y periodistas por el tema estaba, en opinión de Abad Faciolince, relacionado con el horror real al que había llegado la vida en Medellín en ese entonces. Vallejo solo se había encargado de transmitir magistralmente ese horror por la literatura, en la creación de esa pareja gramático/sicario que mostraba la transformación de Medellín en espacio de terror, a causa de la violencia del narcotráfico, como una pesadilla demasiado real. Hablaba también Abad Faciolince de que la novela de Vallejo representaría el fin a la moda de la sicaresca, al mostrar el aspecto delirante de los textos sobre el tema, de la misma manera como El Quijote habría representado el fin de las novelas de caballería. En este sentido su conjetura era equivocada, al menos parcialmente. La virgen de los sicarios quizás sí ofrece una conclusión a la indagación local sobre las prácticas de la violencia entre los sicarios de ese entonces. A la vez, y sin embargo, la novela de Vallejo marca el momento en el cual el tema empieza a ser interpretado y representado en clave global, distanciado de su contexto específico.

Los sicarios como tropo viven su propio tránsito de lo local a lo global. Tras la publicación de La virgen de los sicarios, y en los tiempos en que la novela

8 La cifra de taquilla procede de http://cinecolombiano.com/taquilla/total-1962-a-2013/. Rodrigo $D$ era particularmente difícil de entender porque Víctor Gaviria no hizo concesiones en el uso del lenguaje callejero por parte de sus personajes, todos ellos muchachos procedentes de las comunas de Medellín. Por un lado, este hecho, en sí mismo, habla de una distancia entre estos jóvenes y los espectadores de cine en Colombia, quienes en su mayoría no estaban familiarizados con la forma de hablar de esos muchachos. Por otro lado, el hecho de que los parlamentos de la película fueran más fáciles de entender con subtítulos podría haber llevado a que existiera una muy diferente recepción de la película en países de habla hispana y otros países. También implicaría una diferencia de recepción cuando la película comienza a circular en DVD. 
empieza apenas a circular más allá de Colombia y México, el tema empieza a estar presente en diversos formatos transnacionales. En 1999, y tras una lectura de la novela, Mario Vargas Llosa viaja a Medellín para conocer la iglesia de Sabaneta que visitaban los sicarios, la cual para ese entonces se había convertido casi en una atracción turística. Tras ese viaje, Vargas Llosa publicó al respecto una crónica titulada "Los sicarios", en el periódico El País, de Madrid, donde ofrecía una especie de guía sobre el tema para el lector transnacional. Decía:

$[\ldots]$ los sicarios constituyen también, como los cowboys del Oeste norteamericano o los samuráis japoneses, una mitología fraguada por la literatura, el cine, la música, el periodismo y la fantasía popular, de modo que, cuando se habla de ellos conviene advertir que se pisa ese delicioso y resbaladizo territorio, el preferido de los novelistas, donde se confunden ficción y realidad.

Más que confundir los dos campos, el tono de la columna hace hincapié en el sicario como figura abstracta, disponible para la apropiación desde cualquier contexto.

Otras obras que se publican sobre el tema también destacan este aspecto, no solo fuera, sino también dentro de Colombia. La novela Rosario Tijeras (1999), de Jorge Franco, publicada poco antes de la crónica de Vargas Llosa, se aproxima al tema tratando a los sicarios estrictamente como personajes novelescos. Hay un alejamiento de las prácticas reales de la violencia en su relato, empezando por el hecho de haber construido la trama en torno a una mujer sicario - casi todos los sicarios del narcotráfico eran hombres-. Gira en torno al drama y la pasión, que seducen al lector en una historia de amor complicada por las distancias de clase entre los protagonistas, que viven un triángulo amoroso centrado en Rosario, la mujer sicario. La película basada en esta novela, dirigida por el director mexicano Emilio Maillé, radicaliza aún más esta mitificación de los protagonistas. Sus escenas podrían tener lugar en cualquier lugar, aunque el director fue cuidadoso en reproducir los espacios de Medellín y la forma de hablar de sus habitantes. Es interesante contrastarla con una película anterior sobre el tema, Sicario (1995), realizada en Venezuela por el director uruguayo José Ramón Novoa. Si bien se aleja del realismo al filmar en Caracas y presentar a sus personajes hablando con acento venezolano, esta película muestra una mayor atención a las circunstancias reales de los sicarios de Medellín. Realizada tras la publicación de la novela de Vallejo, y aunque su circulación fue limitada, representa, sin embargo, ya un paso en el salto hacia la transnacionalización del tema. ${ }^{9}$

9 Para un análisis de las distintas películas realizadas sobre el tema de los sicarios, véase el artículo de Héctor Fernández L’Hoeste. 
Esta transnacionalización estaba inscrita y prefigurada en la novela de Vallejo. Si bien los eventos de La virgen de los sicarios se asociaban con las circunstancias locales muy precisas que marcaron su lectura local inicial en Colombia, su recepción global constituía parte del relato y su lenguaje. Vallejo no hablaba solo de los sicarios de Medellín. Su novela anuncia y registra un cambio en las circunstancias sociales de América Latina en la globalización, y también en los parámetros de escritura, publicación y distribución de la literatura en la misma época. En ella Vallejo recrea una literatura que se despega de su circunstancia local inmediata, aunque todavía esté ligada a ella por la filiación del escritor y por las demandas de un mercado que aún espera cierta referencia contextual en la producción literaria. Como el narrador de La virgen de los sicarios, Vallejo se convierte en mercenario de la literatura, de la mano de aquellos jóvenes a quienes en la novela llamaba sus ángeles guardianes. No hay nada de que regocijarse en este proceso, sin embargo. Si bien tanto sus novelas como sus intervenciones públicas incluyen mucho humor, parecen ante todo un largo lamento trágico, escrito en el tono de quien siente demasiado cerca la muerte. El tránsito de lo local a lo global, y viceversa, no parece armonioso, fácil ni deseable. Aunque se realiza a un ritmo vertiginoso, como el exterminio de La virgen de los sicarios, deja a su paso una honda sensación de desasosiego que encuentra su paralelo en la escritura literaria y el lenguaje público de Fernando Vallejo.

\section{Obras citadas}

Abad Faciolince, Héctor. "Lo último de la sicaresca antioqueña".

El Tiempo (Bogotá) 10 de julio de 1994.

Aguilar, Gonzalo. Otros mundos: un ensayo sobre el nuevo cine

argentino. Buenos Aires: Santiago Arcos, 2006.

Alzate, Gastón. "El extremismo de la lucidez: San Fernando

Vallejo". Revista Iberoamericana 74.222 (2008): 1-15.

Bermúdez Barrios, Nayibe, ed. Latin American Cinemas: Local Views and

Transnational Connections. Calgary, Alberta: University of Calgary Press, 2011.

Caballero, Antonio. "Vayan a verla". Semana (Bogotá) 18 de diciembre de 2000.

Collazos, Óscar. "Vallejo, la virgen y los sicarios". El

Tiempo (Bogotá) 19 de octubre de 2000.

Deas, Malcolm. Del poder y la gramática: y otros ensayos sobre historia, política y literatura colombianas. Bogotá: Tercer Mundo, 1993.

Fernández L'Hoeste, Héctor. "From Rodrigo to Rosario: Birth And Rise of the Sicaresca". Revista de Estudios Hispánicos 42.3 (2008): 543-557. 
Foster, Ken. "Barbet Schroeder". BOMB 77 (Fall 2001).

Franca, Andréa y Denilson Lopes. Cinema, globalização e interculturalidade. Chapecó, Brasil: Argos, 2010.

Franco Ramos, Jorge. "La virgen de los colombianos". Semana (Bogotá) 1 de enero de 2001.

-. Rosario Tijeras. Bogotá: Norma, 1999.

"Fuera de foco". Semana (Bogotá) 6 de noviembre de 2000.

García Canclini, Néstor y Ana Rosas Mantecón, eds. Situación actual y perspectivas de la industria cinematográfica en México y en el extranjero. Guadalajara, México: Universidad de Guadalajara and Instituto Mexicano de Cinematografía, 2006.

La desazón suprema: retrato incesante de Fernando Vallejo (2003). Luis Ospina dir.

"La Virgen desde dentro". Semana (Bogotá) 25 de diciembre de 2000.

Newman, Kathleen y Natasa Durovicova. World Cinemas, Transnational Perspectives. Nueva York y Londres: Routledge, 2009.

Ospina, Luis. "Barbet Schroeder en Colombia". El Malpensante 133 agosto de 2012.

Podalsky, Laura. The Politics of Affect and Emotion in Contemporary

Latin American Cinema: Argentina, Brazil, Cuba, and

Mexico. Nueva York: Palgrave MacMillan, 2011.

Rodrigo D: no futuro. Dir. Víctor Gaviria. Focine, Fotoclub-76, Producciones Tiempos Modernos Ltda., 1990.

Rueda, María Isabel. "La virgen". Semana (Bogotá) 5 de febrero de 2001.

Salazar, Alonso. No nacimos pa'semilla Bogotá: CINEP, 1990.

Samper Pizano, Daniel. "Virgen de los sicarios, telebodas y otras yerbas". El Tiempo (Bogotá) 25 de octubre de 2000.

Spitaletta, Reinaldo. "Por fin se apareció la virgen". El Colombiano (Medellín) 2000.

Santamaría, Germán. "Prohibir el sicario". Revista Diners (Bogotá) octubre de 2000, 5.

Schroeder, Barbet. La virgen de los sicarios. Canal+, Les Filmes de

Losange, Proyecto Tucán, Vertigo Films, Tornasol Films 2000.

Shaw, Deborah, ed. Contemporary Latin American Cinema: Breaking into

the Global Market. Lanham, MD: Rowman and Littlefield, 2007.

Vallejo, Fernando. "A los muchachos de Colombia". Peroratas. Madrid: Alfaguara, 2013.

-. La virgen de los sicarios. Bogotá: Alfaguara, 1994.

-. El río del tiempo. Madrid: Alfaguara, 2003.

Vargas Llosa, Mario. "Los sicarios". El País (Madrid), 4 de octubre de 1999.

Von der Walde, Erna. "La novela de los sicarios y la violencia en

Colombia". Iberoamericana, nueva época 1.3 (2001): 27-40. 